RJOAS, 5(113), May 2021

DOI 10.18551/rjoas.2021-05.14

\title{
CORRELATION AND PATH COEFFICIENT ANALYSIS OF YIELD IN WHEAT: A REVIEW
}

\author{
Pandey Rachana \\ Institute of Agriculture and Animal Sciences, Tribhuwan University, Nepal \\ Maharjan Binju*, Acharya Suprava, Bigyan K.C., Pandit Rishav, Regmi Rashmi, \\ Bhusal Bishnu, Neupane Pritika, Bhattarai Kushal \\ Institute of Agriculture and Animal Sciences, Tribhuwan University, Nepal \\ Poudel Mukti Ram \\ Institute of Agriculture and Animal Sciences, Department of Genetics and Plant breeding, \\ Tribhuwan University, Nepal \\ *E-mail: binjumaharjan1@gmail.com
}

\begin{abstract}
A comprehensive study in grain yield potential is crucial in the selection among wheat genotypes. Grain weight alone doesn't decide the portion of economic yield in a harvest index as grain yield is the subtractions of many yield components. Information of associations among traits and yield implies their relative importance for selection in yield improvement. Correlation study is a widely used measure to determine the degree of relationship between various traits. The path analysis is a powerful measure which partitions the correlation coefficient and deals with the relative importance of yield contributing traits on yield. The correlation and path coefficient analysis of grain yield in wheat is reviewed in the paper.
\end{abstract}

\section{KEY WORDS}

Wheat, grain yield, correlation, path coefficient analysis.

Wheat (Triticum aestivum L.) is a staple food to $40 \%$ of the world's population which provides calories and $20 \%$ of daily dietary protein more than any other cereal (LACC/IGW, 2018). With increasing population, individual per capita income and alternative uses of grain the demand of grain has increased (CGIAR, 2020). The expected increase in global demand of grains between 2005-07 and 2050 is 44\% (Fischer et al., 2014). So raising the potential yield through breeding is critical to match the global demand (CGIAR, 2020). Grain yield is a polygenic trait. Knowledge of the mutual association among grain yield and yield attributing traits are important for selection of traits in yield improvement (Baye et al., 2020). Selection based on yield components is deemed to be more effective rather than yield alone (Shamsuddin $\&$ Ali, 1989). This paper reviews on the correlation and path coefficient analysis of yield.

Correlation coefficient analysis of yield. Correlation coefficient analysis is the measurement of the direction and degree of relationships between various traits. It is a widely used measure (Schober et al., 2018). A Pearson correlation is a measure of a linear association between two normally distributed random variables. It is simple, intuitive and is a very popular tool for analyzing data in many scientific disciplines like agriculture, biology, medical sciences, and earth sciences. Correlation study between different characters may help the plant breeder to know how the improvement of one character will bring simultaneous changes in other characters (Sabit et al., 2017). Degree of correlation is categorized as weak (0-0.3), moderate (0.3-0.7) and strong (0.7-1.0). Highly significant correlation among yield attributing traits indicates that, the unit increment in one of the traits will cause a unit increment in the other associated traits. 
Grain yield has positive and highly significant relationship with biological yield followed by harvest Index, thousand kernel weight, number of effective tillers, and spike per meter square whereas grains per spike, flag leaf area, days to maturity, spike length, have positive and significant correlation (Dayem et al.,2021; Maurya et al.,2020; Upadhyay, 2020; Ojha et al., 2019, Joshi et al., 2008, Pandey et al., 2017, Ayer et al., 2017, Kandel et. al., 2018, Khanal et al., 2020, Yadav et al., 2018, Sharma et al., 2017, Ojha et al., 2018, Sharma et al,. 2017, Poudel et al., 2017, Sharma, 1993, Adhikari et al., 2018, Nepali et al., 2018, Shahi et al., 2018). Similarly, days to heading, days to flowering, and days to booting have negative and significant correlation with grain yield (Khanal et al., 2020, Sharma et al., 2017, Adhikari et al., 2018, Nepali et al., 2018, Shahi et al., 2018).

Correlation between yield and plant height. Plant height is one of the most important phenotypic traits in wheat due to its involvement in plant architecture and ultimate grain yield (Bellucci et al. 2015; Hassan et al. 2019). Taller plants capture more radiation for the photosynthesis and also provide shade for avoiding the soil evaporation. Improved photosynthetic ability and radiation use efficiency are regarded as the important trait in other countries for the grain yield (Shearman et al., 2005). There is parabolic relationship of yield with plant height thus there is a range of plant height $(0.7-1 \mathrm{~m})$ that delimits the grain yield. But the high yielding wheat genotypes have already attained the height that favours the grain yield. After attaining certain height the further increase in the plant height decreases the grain yield. It may be because of decrease in mobilization of the carbohydrates towards the reproductive organ for seed formation (Poudel et al., 2017).

Correlation between yield and phenological characters. Wheat has remarkable genetic potential to synchronize its flowering time with favourable environmental conditions which is its key factor for global adaptability. This enables wheat plants to produce satisfactory grain yield under very diverse temperature and soil moisture conditions (Kamran et al., 2014). Early flowering time and a shorter vegetative phase can be very important to escape the impending terminal drought. This can minimize exposure to dehydration during the sensitive flowering and post-anthesis grain filling periods. Under favorable conditions, a short vegetative phase can result in reduced plant biomass due to the reduction in time available for photosynthetic production and seed nutrient accumulation. However, high yield potential has been reported for the development of both shallow and deep roots, representing plasticity in response to drought in combination with the early flowering trait (Shavrukov et al., 2017).

Grain yield has a highly significant and positive correlation with the number of effective tillers. Tillers are formed in a specific development sequence (Darwinkel, 1978; Power and Alessi, 1978; Simons, 1982). Those formed at later stages may die prematurely. Such tillers and the non-reproductive tillers may have negative effects as they compete for assimilates and plant nutrients (Langer and Dougherty, 1976). Among yield attributing components, productive tillers are very important because the final yield is mainly a function of the number tillers bearing spike per unit area (Pandey et al., 2017).

Moreover, the negative correlation between days to heading and grain yield and the positive correlation between days to maturity and grain yield both could be attributed to the longer grain filling period which is permitted by early heading and late maturity. Grain filling period is an important phase in the life cycle of a wheat plant. It is the duration of the reproductive phase when the accumulation of photosynthate and its partitioning into grain is determined (Sharma 1994). During this period photosynthetic component remain green; improving the grain filling because the contribution of post anthesis assimilates is important to grain yields in cereals.

Early heading and late maturing genotypes have longer grain filling period but these only influence kernel weights. Sharma et al. (2017) reported that the lines with long grain filling period always had higher average kernel weight and harvest index. But they reported that some lines with long GFP and low yield which could be due to differential grain filling rate. Extended 
pre heading period would be better for increasing grain yield than extended grain fill period (Karaki, 2012). The competition for assimilates between stem and spike is reduced and there is greater partitioning of grain yield to the spike (Gonzalez et al. 2003a; Gonzalez et al., 2003b). Spikelet fertility is closely associated with period of spikelet initiation to heading (stem elongation). So the longer stem elongation phase increase number of grains per spike.

Correlation between yield and yield related traits. Grain yield was strongly correlated with spike per $\mathrm{m}^{2}$ but not with grains per spike. Spike per $\mathrm{m}^{2}$ represent the spike present in an area of one meter and is also a clear indication of the spike density which is directly proportional with the grain yield. Spike density influences the total dry matter of wheat than average kernel weight. Donald (1962) first defined the harvest index as the economic yield of a wheat crop expressed as a decimal fraction of total biological yield. Thus crop yield can be increased either by increasing the total dry matter accumulation or by increasing the proportion of economic yield in whole fraction of biological yield. Harvest index can also be referred as migration coefficient. It refers to how much of dry matter accumulated is mobilized or migrated towards the kernels (Taiz et al., 2015).

Sharma (1993) conducted a study to determine the response to selection for high and low biomass yield in eight genetically diverse populations of spring wheat under two production systems. Based on their biomass yield, the 30 highest and 30 lowest scoring F3 lines were selected and they were tested in F4 under a high and a low fertility production system. Grain yields of the high and low biomass selection groups differed in each population under both production systems. Within a given climatic zone, harvest index has been found to be a stable feature of wheat and barley cultivars, in the absence of severe stress or abnormal chemical treatments (Gallagher \& Biscoe, 1978b). Despite a theoretical upper limit (0.62; Austin et al., 1980), it appears difficult to achieve $\mathrm{HI}$ of values higher than 0.50 (Fischer \& Edmeades, 2010). Hence, future genetic gains in grain yield would depend on increasing biomass production while maintaining $\mathrm{HI}$.

Path coefficient analysis. Path coefficient is a standard partial regression analysis that partitions the correlation coefficient into direct and indirect effects (Falconer and Mackay, 1996). The concept was first used in plant selection by Dewey and Lu in 1959 but the concept was originally developed by Wright in 1921. It has emerged as powerful and widely used measure to understand the relative importance of different parameters as selection criteria for yield ( Maurya et al.,2020; Upadhyay, 2020). Grain yield is a complex quantitative trait hence multiple traits are needed to be considered for its improvement. Since correlation study alone doesnot depict the clear picture of the relationship among traits and path coeffficient analysis serves as an important tool for formulating efficient selection strategy. Correlation provides linear relationship which shows degree and direction of relationship between paired values in a sample. But path analysis shows the direct and indirect effects of independent variables on dependent variables (Upadhyay, 2020).

Studies have reported that plant height, flag leaf area, days to flowering, $50 \%$ heading, days to maturity, peduncle length, spike length, spike per meter, number of spikelets per spike grain-filling periods, grain weight per spike, biological yield, and harvest index had positive direct effect on grain yield indicating the relationship between these traits as good contributors to grain yield (Dayem et al., 2021; Baye et al., 2020 ; Sabit et al., 2017 and Mecha et al., 2017 ). Harvest index had the highest positive direct effect on grain yield followed by biomass yield (Dayem et al., 2021; Abinasa et al.,, 2011; Leilah and Al-Khateeb 2005 and Dutamo et al.,2015). Selection based on these traits may be effective for yield improvement in bread wheat.

Days to maturity and thousand seed weight had negative direct effect on grain yield (Wolde et al., 2016; Baye et al.,2020; Kotal et al. 2010, Dabi et al. 2016, and Sabit et al. 2017). However, these contradicted the results of Mecha et al. (2017) and Khan et al., (2013) as they reported positive direct effect of both days to maturity and thousand seed weight on grain yield. 
This implies that the effect of yield-related traits on grain yield may be influenced by environment (Baye et al., 2020).

Dayem et al., (2021) reported days to maturity via plant height, number of spikes via number of kernels/spike had indirect positive effects on grain yield. In contrast Maurya et al., (2020) reported direct positive effect of days to maturity. Similarly, spike length, number of spikes $/ \mathrm{m}^{2}$ and thousand kernel weights had the positive direct effect (Kumar et al., 2014; Dayem et al., 2021; Maurya et al., 2020).

\section{CONCLUSION}

Effective selection is important for yield improvement in plant breeding. Information of associations among traits and yield clarifies their relative importance for selection in yield improvement. Test weight, days to maturity, spike per meter square, effective tiller, and days to flowering and heading, biomass and harvest index are correlated with yield so can be considered as the good estimates for effective selection of high yielding wheat genotypes. Path analysis showed that plant height, flag leaf area, days to flowering, $50 \%$ heading, days to maturity, peduncle length, spike length, spike per meter, number of spikelets per spike, grainfilling periods, grain weight per spike, biological yield, and harvest index had positive direct effect on grain yield. These traits could be considered as good contributors to grain yield.

\section{AUTHORS CONTRIBUTIONS}

The idea was proposed by Mukti Ram Poudel. The review was designed by Rachana Pandey and Binju Maharjan. All other authors have equally assisted in the article preparation. Every single topic under the review paper has been written under the combine discussion of all authors.

\section{ACKNOWLEDGEMENTS}

We would like to express our heartiest gratitude, and respect to our beloved parents for their continuous encouragements, love, blessings, and never ending faith that has been the perennial source of inspiration in building our academic career.

\section{COMPETING INTERESTS}

Authors declare that they have no potential competing interest related to presented study.

\section{REFERENCES}

1. Abinasa, M., Ayana, A., \& Bultosa, G. (2011). Genetic variability, heritability and trait associations in durum wheat (Triticum turgidum L. var. durum) genotypes. African Journal of Agricultural Research, 6(17), 3972-3979.

2. Adhikari, B. N., Joshi, B. P., Shrestha, J., \& Bhatta, N. R. (2018). Genetic variability, heritability, genetic advance and trait association study for yield and yield components in advanced breeding lines of wheat. Nepalese Journal of Agricultural Sciences, 17, 229-238.

3. Al-Karaki, G. N. (2012). Phenological development-yield relationships in durum wheat cultivars under late-season high-temperature stress in a semiarid environment. International Scholarly Research Notices, 2012.

4. Austin, R. B., Bingham, J., Blackwell, R. D., Evans, L. T., Ford, M. A., Morgan, C. L., \& Taylor, M. (1980). Genetic improvements in winter wheat yields since 1900 and associated physiological changes. The journal of agricultural science, 94(3), 675-689. 
5. Ayer, D. K., Sharma, A., Ojha, B. R., Paudel, A., \& Dhakal, K. (2017). Correlation and path coefficient analysis in advanced wheat genotypes. SAARC Journal of Agriculture, 15(1), 112.

6. Baloch, M. J., Chandio, I. A., Arain, M. A., Baloch, A., \& Jatoi, W. A. (2016). Effect of terminal drought stress on morpho-physiological traits of wheat genotypes. Biological Sciences-PJSIR, 59(3), 117-125.

7. Baye, A., Berihun, B., Bantayehu, M., \& Derebe, B. (2020). Genotypic and phenotypic correlation and path coefficient analysis for yield and yield-related traits in advanced bread wheat (Triticum aestivum L.) lines. Cogent Food \& Agriculture, 6(1), 1752603.

8. Bellucci A, Torp AM, Bruun S, Rasmussen SK (2015) Association mapping in Scandinavian winter wheat for yield, plant height, and traits important for second-generation bioethanol production frontiers in plant. Science 6:1-12

9. CAS Secretariat (CGIAR Advisory Services Shared Secretariat). (2020). CGIAR Research Program 2020 reviews: WHEAT, Rome: CAS Secretariat Evaluation Function

10. Dabi, A., Mekbib, F., \& Desalegn, T. (2016). Estimation of genetic and phenotypic correlation coefficients and path analysis of yield and yield contributing traits of bread wheat (Triticum aestivum L.) genotypes. International Journal of Natural Resource Ecology and Management, 1(4), 145-154.

11. Darwinkel, A. (1978). Patterns of tillering and grain production of winter wheat at a wide range of plant densities. NJAS wageningen journal of life sciences, 26(4), 383-398.

12. Dayem, A. E.L., Gohary, Y. A. E.L., \& Ibrahim, H. E. (2021). Path-Coefficient Analysis and Correlation Studies on Grain Yield and its Components of some Bread Wheat Genotypes under Three Irrigation Treatments. Journal of Plant Production, 12(2), 115-123.

13. Dougherty, C. T., Love, B. G., \& Mountier, N. S. (1978). Response surfaces of semidwarf wheat for seeding rate, and levels and times of application of nitrogen fertiliser. New Zealand journal of agricultural research, 21(4), 655-663.

14. Dutamo, D., Alamerew, S., Eticha, F., \& Assefa, E. (2015). Path coefficient and correlation studies of yield and yield associated traits in bread wheat (Triticum aestivum L.) germplasm. World Applied Sciences Journal, 33(11), 1732-1739.

15. Falconer, D.S. \& Mackay, T.F.C. (1996). Introduction to quantitative genetics. Ed. 4. Longman.

16. Fischer, R. A., \& Edmeades, G. O. (2010). Breeding and cereal yield progress. Crop Science, 50, S-85.

17. Fischer, R.A., Byeriee, D., \& Edmeades, G.O. (2014). Crop yields and global food security. Will yield increase continue to feed the world? ACIAR, Canberra.

18. Flintham, J. E., Börner, A., Worland, A. J., \& Gale, M. D. (1997). Optimizing wheat grain yield: effects of Rht (gibberellin-insensitive) dwarfing genes. The Journal of Agricultural Science, 128(1), 11-25.

19. Gallagher, J. N., \& Biscoe, P. V. (1978b). A physiological analysis of cereal yield. II. Partitioning of dry matter. Agricultural progress, 53, 51-70.

20. Gonzalez FG, Slafer GA, Miralles DJ (2003a) Grain and floret numbering response to photoperiod during stem elongation in fully and slightly vernalized wheats. Field Crops Res $81: 17-27$.

21. Gonzalez FG, Slafer GA, Miralles DJ (2003b) Floret development and spike growth as affected by photoperiod during stem elongation in wheat. Field Crops Res 81:29-38.

22. Hassan, M. A., Yang, M., Fu, L., Rasheed, A., Zheng, B., Xia, X., ... \& He, Z. (2019). Accuracy assessment of plant height using an unmanned aerial vehicle for quantitative genomic analysis in bread wheat. Plant Methods, 15(1), 1-12.

23. Joshi, B. K., Mudwari, A., \& Thapa, D. B. (2008). Correlation and path coefficients among quantitative traits in wheat (Triticum aestivum L.). Nepal Journal of Science and Technology, $9,1-5$. 
24. Kamran, A., Iqbal, M., \& Spaner, D. (2014). Flowering time in wheat (Triticum aestivum L.): a key factor for global adaptability. Euphytica, 197(1), 1-26.

25. Kandel, M., Bastola, A., Sapkota, P., Chaudhary, O., Dhakal, P., \& Chalise, P. (2017). Association and path coefficient analysis of grain yield and its attributing traits in different genotypes of wheat (Triticum aestivum L.). International Journal of Applied Sciences and Biotechnology, 5(4), 449-453.

26. Khanala, D., Thapab, D. B., Dhakala, K. H., \& Kandelc, M. P. P. B. P. (2020). Correlation And Path Coefficient Analysis Of Elite Spring Wheat Lines Developed For High Temperature Tolerance. Environment \& Ecosystem Science (EES), 4(2), 73-76.

27. Khan, A. A., Alam, M. A., Alam, M. K., Alam, M. J., \& Sarker, Z. I. (2013). Correlation and path analysis of durum wheat (Triticum turgidum L. var. Durum). Bangladesh Journal of Agricultural Research, 38(3), 515-521.

28. Kumar, R., Bhushan, B., Pal, R. and Gaurav, S.S. (2014). Correlation and path coefficient analysis for quantitative traits in wheat (Triticum aestivum L.) under normal condition. Annals of Agri Bio Research, 19(3): 447-450.

29. Kotal, B. D., Arpita, D., \& Choudhury, B. K. (2010). Genetic variability and association of characters in wheat (Triticum aestivum L.). Asian journal of crop science, 2(3), 155-160.

30. LACC/IGW. (2018). 4th Latin American Cereals Conference. Book of Abstracts. CDMX, Mexico: International Maize and Wheat Improvement Center (CIMMYT).

31. Leilah, A. A., \& Al-Khateeb, S. A. (2005). Statistical analysis of wheat yield under drought conditions. Journal of Arid environments, 61(3), 483-496.

32. Maurya, A. K., Yadav, R. K., Singh, A. K., Deep, A., \& Yadav, V. (2020). Studies on correlation and path coefficients analysis in bread wheat (Triticum aestivum L.). Journal of Pharmacognosy and Phytochemistry, 9(4), 524-527.

33. Mecha, B., Alamerew, S., Assefa, A., Dutamo, D., \& Assefa, E. (2017). Correlation and path coefficient studies of yield and yield associated traits in bread wheat (Triticum aestivum L.) genotypes. Adv Plants Agric Res, 6(5), 1-10.

34. Miralles, D. J. \& Slafer, G. A. (1999). Wheat development In Wheat: Ecology and Physiology of Yield Determination (Eds E. H. Satorre \& G. A. Slafer),13-43.New York: Food Product Press.

35. Nepali, M. R., Ojha, B. R., Adhikari, N. R., \& Baral, K. (2015). Screening of wheat (triticum aestivum I.) Genotypes with morhpho-physiological traits under irrigated and rainfed conditions in rampur, chitwan. Technical publication thesis grants.

36. Ojha, B. R., Ojha, A., \& Chaudhary, R. (2019). Variability, heritability and correlation studies on grain yield and related traits in spring wheat genotypes. Journal of Agriculture and Forestry University, 3, 57.

37. Ojha, R., Sarkar, A., Aryal, A, K.C., R, Tiwari, S., Poudel, M., ... \& Shrestha, J. (2018). Correlation and path coefficient analysis of wheat (Triticum aestivum L.) genotypes. Farming and Management, 3(2), 136-141.

38. Pandey, G., Yadav, L., Tiwari, A., Khatri, H. B., Basnet, S., Bhattarai, K., ... \& Khatri, N. (2017). Analysis of yield attributing characters of different genotypes of wheat in Rupandehi, Nepal. International Journal of Environment, Agriculture and Biotechnology, 2(5), 238915.

39. Poudel, A., Ghimire, S. K., Ojha, B. R., Acharya, B. D., \& Thapa, D. B. (2017). Effect of Terminal Drought Stress on Morpho-Physiological and Yield Potential Traits of Bread Wheat Genotypes.

40. Power, J. F., \& Alessi, J. (1978). Tiller development and yield of standard and semidwarf spring wheat varieties as affected by nitrogen fertilizer. The Journal of Agricultural Science, 90(1), 97-108.

41. Richards, R. A. (1992). The effect of dwarfing genes in spring wheat in dry environments. I. Agronomic characteristics. Australian Journal of Agricultural Research, 43(3), 517-527. 
42. Sabit, Z., Yadav, B. and Rai, P.K. (2017). Genetic variability, correlation and path analysis for yield and its components in $f 5$ generation of bread wheat (Triticum aestivum $L$.) Journal of Pharmacognasy and Phytochemistry, 6(4): 680-687, https://doi.org/10.9790/23801201011723.

43. Schober, P., Boer, C., \& Schwarte, L. A. (2018). Correlation coefficients: appropriate use and interpretation. Anesthesia \& Analgesia, 126(5), 1763-1768.

44. Shahzad, K., Bakht, J., Shah, W. A., Shafi, M., \& Jabeen, N. (2002). Yield and yield components of various wheat cultivars as affected by different sowing dates. Asian Journal of Plant Sciences.

45. Shahi, D., Ghimire, S. K., Ojha, B. R., Bhatta, M. R., Rasaily, S., Rauniyar, D. R., \& Sapkota, M. (2018). Evaluation of variability and genetic parameters for yield and yield-attributing traits in spring wheat (Triticum aestivum L.). Nepalese Journal of Agricultural Sciences 2018, volume 17, 134.

46. Shamsuddin, A. K. M., \& Ali, M. M. (1989). Genotypic and phenotypic correlation and path analysis in spring wheat. Bangladesh J. Agril. Sci, 16(1), 75-78.

47. Sharma, R. C. (1993). Selection for biomass yield in wheat. Euphytica, 70(1), 35-42.

48. Sharma, R. C. (1994). Early generation selection for grain-filling period in wheat. Crop science, 34(4), 945-948.

49. Sharma, S., Acharya, N. R., Adhikari, S., \& Mishra, K. K. (2017). Varietal improvement of wheat under rainfed conditions in mid-western terai of Nepal. Global Journal of Biology, Agriculture and Health Sciences, 6(4), 15-19.

50. Shavrukov, Y., Kurishbayev, A., Jatayev, S., Shvidchenko, V., Zotova, L., Koekemoer, F., ... \& Langridge, P. (2017). Early flowering as a drought escape mechanism in plants: How can it aid wheat production?. Frontiers in plant science, 8, 1950.

51. Shearman, V. J., Sylvester-Bradley, R., Scott, R. K., \& Foulkes, M. J. (2005). Physiological processes associated with wheat yield progress in the UK. Crop science, 45(1), 175-185.

52. Simons, R. G., \& Hunt, L. A. (1983). Ear and tiller number in relation to yield in a wide range of genotypes of winter wheat. Zeitschrift fur Pflanzenzuchtung= Journal of plant breeding.

53. Subhani, G. M. (2000). Correlation and path coefficient analysis in bread wheat under drought stress and normal conditions. Pakistan Journal of Biological Sciences (Pakistan).

54. Taiz, L., Zeiger, E., Møller, I. M., \& Murphy, A. (2015). Plant physiology and development (No. Ed. 6). Sinauer Associates Incorporated.

55. Upadhyay, K. (2020). Correlation and path coefficient analysis among yield and yield attributing traits of wheat (Triticum aestivum L.) genotypes. Archives of Agriculture and Environmental Science, 5(2), 196-199.

56. Wolde, T., Eticha, F., Alamerew, S., Assefa, E., Dutamo, D., \& Mecha, B. (2016). Trait associations in some durum wheat (Triticum durum L.) accessions among yield and yield related traits at Kulumsa, south eastern Ethiopia. Advances in Crop Science and Technology, 2016.

57. Yadav, R. P., Pandey, M. P., \& Ojha, B. R. Evaluation of Bio-fortified Wheat Genotypes for Grain Yield, Zinc and Iron Content. 